\title{
APLIKASI MOBILE PENJUALAN PRODUK PADA HANAKA CONCEPT STORE DENGAN FITUR GAMIFICATION
}

\author{
Putu Agus Indra Purnama ${ }^{1}$, Duman Care Khrisne ${ }^{2}$, I Gusti Komang Diafari Djuni ${ }^{3}$ \\ Jurusan Teknik Elektro, Fakultas Teknik, Universitas Udayana Denpasar - Bali \\ Email : putuagus indrapurnama@ymail.com ${ }^{1}, \underline{\text { duman@unud.ac.id }}^{2}{ }$ igakdiafari@ee.unud.ac.id $^{3}$
}

\begin{abstract}
ABSTRAK
Hanaka concept store merupakan sebuah perusahaan yang bergerak di bidang fashion di Bali, yang berdiri sejak 19 Maret 2013 yang beralamat di jalan Tukad Pakerisan No. 54 Denpasar, Bali. Persaingan di dunia fashion membuat Hanaka concept store dituntut untuk menjadi yang berbeda dalam hal fashion dan pemasaran produk. Penelitian ini bertujuan untuk membangun sistem penjualan produk berbasis aplikasi mobile pada Hanaka Concept Store. Sistem yang dibangun menggunakan metode gamification agar dapat membuat proses pemasaran produk menjadi lebih menarik untuk customer. Metode gamification yang terdapat pada aplikasi ini berupa pemberian point terhadap aktifitas-aktifitas yang dilakukan oleh customer baik itu transaksi pemesanan produk maupun quest-quest. Dari hasil implementasi sistem dan pengisian kuisioner terhadap customer, mendapatkan skor nilai 4.41 yang dalam hal ini sangat setuju dengan adanya aplikasi mobile yang terdapat fitur gamification.

Kata kunci: e-commerce, Gamification, Sistem Informasi Penjualan.
\end{abstract}

ABSTRACT

Hanaka concept store is a company engaged in the field of fashion in Bali, which was established since March 19, 2013 which is located at Jalan Tukad Pakerisan No. 54 Denpasar, Bali. Competition in the world of fashion makes Hanaka concept store is required to be different in terms of fashion and product marketing. This study aims to build mobile product-based product sales system at Hanaka Concept Store. The system is built using the method of gamification in order to make the product marketing process becomes more attractive to the customer. Gamification methods contained in this application in the form of providing point to the activities undertaken by the customer either the transaction product order or quest-quest. From the results of system implementation and charging questionnaires to customers, get a score of 4.41 which in this case strongly agree with the existence of mobile applications that feature gamification.

Keywords: e-commerce, Gamification, Sales Information System.

\section{PENDAHULUAN}

Fashion merupakan salah satu industri yang penting dalam pengembangan industri kreatif indonesia [1]. Salah satu provinsi yang berhasil mengembangkan industri fashion adalah provinsi Bali, bukti nyata atas perkembangan pesat industri fashion di Bali adalah pesatnya pertumbuhan FO (fashion outlet) dan Distro (distribution store) sebagai agen distribusi produk tekstil yang mengandalkan kreatifitas. Hanaka concept store merupakan sebuah perusahaan yang bergerak di bidang fashion di Bali, yang berdiri sejak 19 maret 2013 yang beralamat di jalan Tukad Pakerisan No. 54 Denpasar, Bali. Berusaha mengenalkan budaya baru pada dunia fashion yang disebut urban, yaitu suatu tren fashion yang tidak mementingkan gambar desain tetapi lebih fokus pada kombinasi kain.
Banyaknya pesaing didunia fashion membuat Hanaka concept store dituntut untuk menjadi yang berbeda dalam hal fashion dan pemasaran produk. Namun hingga saat ini dalam proses pengelolaan data, dan pemasaran produk Hanaka concept store masih dalam proses konvensional. Proses konvensional yang dimaksud adalah pemasaran hanya dilakukan melalui media sosial saja. Proses konvensional ini juga dilakukan oleh banyak pesaing lain di dunia fashion, dan belum terdapat perbedaan dalam proses pemasaran untuk menarik konsumen.

Untuk membentuk teknik pemasaran yang berbeda dan menarik minat konsumen dibutuhkan suatu sistem dan metode yang dapat mengatur pengelolaan data barang hingga proses pemasaran, agar dapat meningkatkan penjualan pada Hanaka concept 
store. Sistem tersebut dapat melakukan pengelolaan data barang dan pemasaran secara online (e-commerce) [2]. Ditambah metode untuk meningkatkan pemasaran yang disebut gamification. Gamification merupakan suatu metode pemanfaatan game (metode dan mekanisme) untuk menyelesaikan permasalahan-permasalahan pada banyak bidang khususnya pemasaran [3].

Berdasarkan ketiga hasil penelitian tersebut sebagian besar sistem informasi yang dibangun berbasis web dengan menggunakan bahasa pemrograman PHP, CSS, Java dan menggunakan database MySQL. Selain itu masing-masing sistem informasi yang dibuat memiliki fokus tujuan yang berbeda. Pada penelitian Pratiwi [4] memiliki tujuan untuk memasarkan barang dan jasa dari banyak toko bunga yang sudah mendaftar secara online ke sistem. Pada penelitian Hastanti [5] memiliki tujuan merancang dan membuat media promosi dan penjualan berbasis web di Tata Distro yang mudah diakses oleh konsumen. Pada penelitian Romdhoni [6] memiliki tujuan penerapan gamification pada e-learning agar pengguna merasa senang dan tidak bosan saat menggunakannya sehingga pengguna bersemangat dan terus menggunakan aplikasi tersebut.

Berbeda dengan penelitian yang telah ada sebelumnya, pada penelitian ini sistem informasi yang dibangun akan mengadopsi dari ketiga hasil penelitian di atas. Sistem informasi yang dibangun berbasis Android menggunakan Macromedia Dreamweaver untuk mendesain tampilan website, Intel XDK digunakan untuk editor aplikasi android, PhoneGap digunakan sebagai framework open source yang dipakai untuk membuat aplikasi cross-platform mobile. Sistem informasi yang dibangun menggunakan bahasa pemrograman PHP, HTML, CSS, Java dan MySQL sebagai database. Sedangkan tujuan penelitian ini digunakan untuk membangun konsep gamification pada Hanaka Concept Store berbasis Android.

Proses gamification yang akan di bangun adalah setiap pembelian produk pada Hanaka concept store akan diberikan poin. Setelah itu pembeli memasukan kode voucher yang diberikan lalu diinputkan ke dalam sistem. Poin ini berguna untuk mendapatkan peringkat pada leaderboard yang akan membuat persaingan pada pembeli dengan hadiah yang akan dibagikan setiap bulannya.
Leaderboard juga akan direset setiap bulannya untuk mencari peringkat dan pemenang yang baru.

\section{KAJIAN PUSTAKA}

\subsection{E-Commerce}

E-Commerce merupakan insiatif untuk mengubah paradigm transaksi jual beli dan pembayaran dari cara konvensional ke dalam bentuk digital elektronik berbasiskan komputer dan jaringan internet [2].

\subsection{Gamification}

Gamification merupakan sebuah teknik yang menerapkan game mechanic untuk aktifitas non-game context guna merubah perilaku masyarakat [3]. Risal mendefinisikan gamification sebagai sebuah proses yang bertujuan mengubah non-game context menjadi jauh lebih menarik dengan mengintegrasikan game thinking, game design, dan game mechanics. Gamification merupakan strategi baru yang penting dan kuat untuk mempengaruhi dan memotivasi seseorang atau kelompok masyarakat [7].

\section{METODE PENELITIAN}

Data penelitian ini bersumber dari pemilik Hanaka Concept Store. Jenis data yang digunakan adalah data sekunder yaitu berupa katalog-katalog data tentang produk ada di Hanaka Concept Store dan wawancara dengan pemilik Hanaka Concept Store.

Adapun tahapan penelitian dapat dilihat pada Gambar 1.

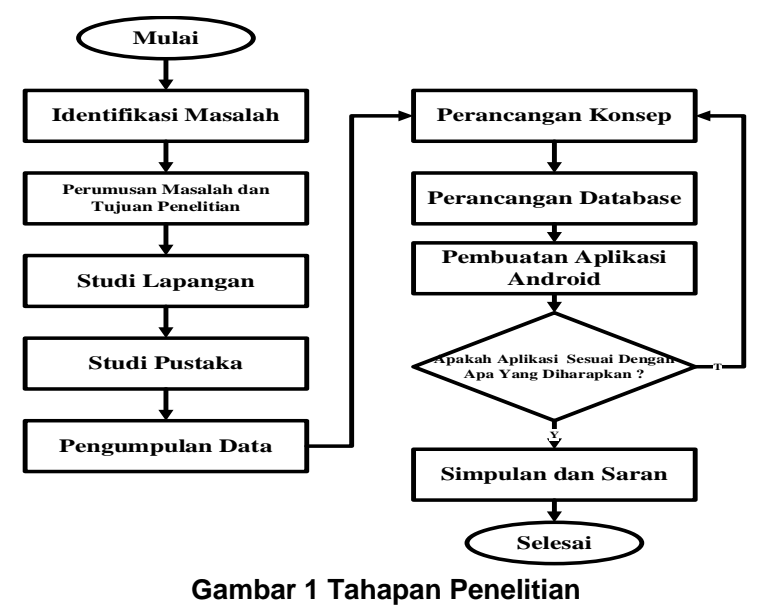




\subsection{Gambaran Umum Sistem}

Aplikasi mobile penjualan produk pada hanaka concept store dengan fitur gamification ini memiliki beberapa fitur yang dapat membantu konsumen dalam melakukan transaksi pemesanan dan memiliki mobilitas kerja tinggi, dengan aplikasi ini konsumen dapat melakukan banyak pemesanan barang dalam sekali transaksi dari Hanaka Concept Store yang sudah tersedia oleh sistem. Adapun gambaran umum sistem dapat dilihat pada Gambar 2.

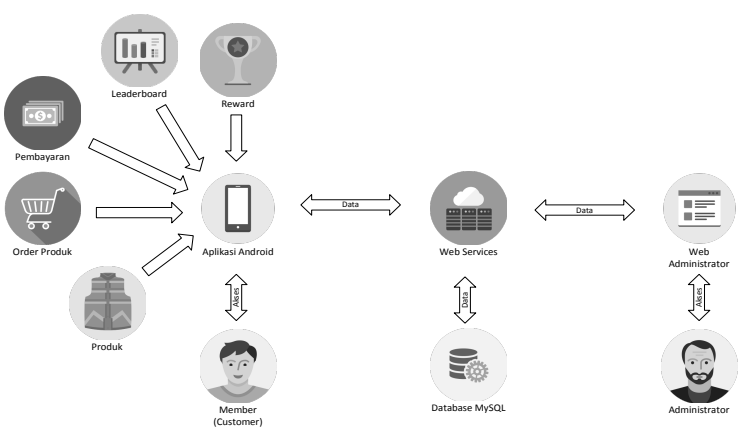

Gambar 2 Gambaran Umum Sistem

Pembeli atau customer melakukan transaksi dengan memilih produk dari Hanaka concept store yang sudah disediakan oleh sistem. Pemesanan bisa dilakukan lebih dari satu produk dengan menggunakan konsep "Keranjang Belanja", kemudian sistem melakukan pemberitahuan kepada Hanaka concept store bahwa sudah terjadi transaksi. User admin melakukan maintanence seperti menambah produk, melakukan konfirmasi transaksi pada pembeli, dan reporting pada sistem web ini.

Pada aplikasi android, sistem memiliki menu halaman leaderboard yang menampilkan informasi point member yang tertinggi. Untuk memperoleh serta menambah point member, pertama-tama member melakukan pemesanan produk yang dijual oleh Hanaka Concept Store, Ialu memilih alamat tujuan pengiriman produk yang dipesan. Setelah member melakukan pemesanan produk dan memilih alamat tujuan pengiriman, sistem akan menjumlahkan total biaya yang harus dibayar oleh member. Selain halaman leaderboard, pada sistem juga terdapat halaman quest dan halaman events yang berfungsi untuk mengetahui tata cara mendapatkan bonus point. Dan halaman promosi yang berfungsi untuk member agar dapat mendapatkan point tambahan selain dengan cara berbelanja di Hanaka Concept Store.

Proses selanjutnya adalah proses pembayaran, proses pembayaran ini melalui sistem pembayaran transfer ke rekening pemilik atau admin hanaka concept store. Setelah melakukan transfer, selanjutnya member diharuskan untuk melakukan konfirmasi pembayaran melalui aplikasi. Jika member telah melakukan pembayaran serta konfirmasi pembayaran, maka admin toko akan melakukan konfirmasi bahwa member telah membayar, serta mengirim produk yang dipesan serta secara otomatis sistem akan menambah point member berdasarkan produk yang dipesan. Artinya point akan diberikan jika member telah melakukan pemesanan produk serta telah melakukan pembayaran. Besarnya point tidak berdasarkan harga produk, namun besarnya point berdasarkan kategori produk. Sehingga jika terdapat beberapa produk yang berbeda tetapi tetap satu kategori, maka point yang didapat oleh member tetap sama.

Hadiah yang diberikan berdasarkan jumlah point yang diperoleh oleh member. Jumlah point pada member akan dikurangi atau direset setelah proses pemberian hadiah sudah diberikan kepada member.

Proses pemberian hadiah ini dilakukan oleh pihak hanaka concept store tiap-tiap periode. Periode ini bisa selama tiga bulan, enam bulan, bahkan bisa hanya selama satu bulan, tergantung event-event yang diadakan oleh pihak Hanaka Concept Store

\section{HASIL DAN PEMBAHASAN}

4.1. Rules Gamication

Rules gamification pada aplikasi mobile penjualan produk pada Hanaka Concept Store dengan fitur gamification ini dapat dilihat pada Gambar 3 dibawah ini: 


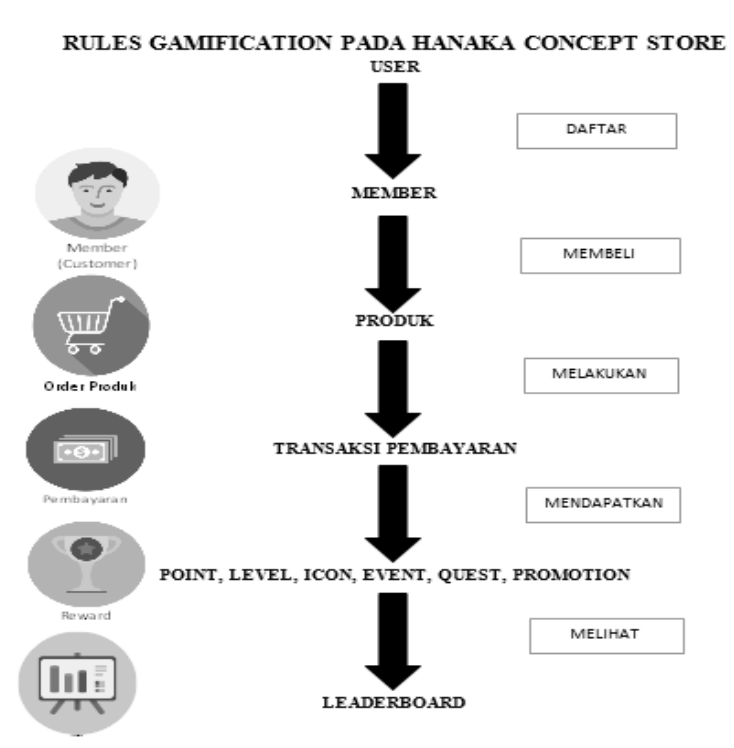

Gambar 3 Rules Gamification

a. User atau customer diwajibkan terlebih dahulu menjadi member Hanaka Concept Store dengan cara mendaftar pada sistem.

b. Untuk mendapatkan point member diharuskan untuk membeli produk Hanaka Concept Store.

c. Point pada setiap produk ditentukkan oleh kategori produk. Jadi setiap kategori memiliki point yang berbeda-beda. Point pada kategori produk bisa kita lihat pada Tabel 1.

Tabel 1 Point Kategori Produk

\begin{tabular}{|c|l|c|c|}
\hline No & \multicolumn{1}{|c|}{ Kategori } & Point & $\begin{array}{c}\text { Bonus } \\
\text { Point }\end{array}$ \\
\hline 1 & Kaos & 100 & 0 \\
\hline 2 & Celana Pendek & 150 & 0 \\
\hline 3 & Celana Panjang & 180 & 0 \\
\hline 4 & & & \\
\hline 5 & Jaket & 200 & 0 \\
\hline 6 & Temeja & 180 & 0 \\
\hline 7 & Limited & 120 & 0 \\
\hline & & 250 & $100-$ \\
& & & 200 \\
\hline
\end{tabular}

Dari Tabel 1 point di tentukan oleh kategori produk. Khusus untuk kategori produk limited akan mendapatkan bonus point. Bonus point merupakan point tambahan yang diberikan

\begin{tabular}{|c|c|c|}
\hline No & Level & Point \\
\hline 1 & Beginner & $0-1000$ \\
\hline 2 & Elementary & $1001-2500$ \\
\hline 3 & Intermediate & $2501-4500$ \\
\hline 4 & Advanced & $>4500$ \\
\hline
\end{tabular}

diluar point yang terdapat pada setiap kategori produk. Rentang bonus point pada kategori limited adalah antara 100-200 point. Bonus point pada kategori limited ditentukan oleh produk Hanaka Concept Store.

d. Member yang telah melakukan order produk dan melakukan konfirmasi pembayaran akan mendapatkan point sesuai dengan kategori barang yang dibeli. Member akan mendapatkan point ketika telah menyelesaikan konfirmasi pembayaran.

e. Setelah mendapatkan point, member juga akan mendapatkan level. Level ditentukan sesuai dengan jumlah point yang didapatkan oleh member. Besarnya Level pada member ditentukan oleh banyaknya point yang dimiliki oleh member. Semakin banyak point yang dimiliki oleh member, maka semakin besar juga Level member tersebut. Level pada member bisa kita lihat pada Tabel 2. Untuk level beginner rentang point yang dibutuhkan oleh member adalah 0-1000 point, level elementary rentang point antara 1001-2500 point, level intermediate rentang point antara 2501-4500 point, dan level advanced rentang point diatas 4500 point.

\section{Tabel 2 Level Member}

Untuk level beginner rentang point yang dibutuhkan oleh member adalah 0-1000 point, level elementary rentang point antara 10012500 point, level intermediate rentang point antara 2501-4500 point, dan level advanced rentang point diatas 4500 point.

f. Setelah mendapatkan point dan level, member juga akan mendapatkan icon. Icon merupakan tampilan lencana member dalam bentuk gambar atau ikon. Gambar atau ikon yang ditampilkan berdasarkan pada level yang dimiliki oleh member.

g. Selain point, level dan icon pada sistem juga terdapat event dan quest. Event merupakan informasi yang diberikan pada member untuk mendapatkan bonus point yang dilakukan 
hanya pada waktu tertentu saja dan berlangsung pada waktu yang relatif lebih singkat. Bonus point yang didapatkan member akan lebih banyak ketika menyelesaikan event karena waktu berlangsungnya event ini relatif singkat antara 1 sampai dengan 5 hari tergantung dari event yang akan diadakan. Bonus point yang didapatkan jika telah menyelesaikan event adalah 200 point. Quest ini merupakan arahan dan tolak ukur performansi member. Quest akan menampilkan beberapa pengetahuan tentang tata cara mendapatkan point tambahan untuk menaikkan level. Berbeda dengan event, quest berlangsung dengan jangka waktu yang relatif lama antara 1 sampai dengan 12 bulan. Dan bonus point yang didapat pada quest lebih kecil dibandingkan bonus yang didapat pada event, karena quest berlangsung dalam jangka waktu yang relatif lama. Bonus point yang didapatkan jika telah menyelesaikan quest adalah 100 point setiap questnya. Jika sudah menyelesaikan quest, maka point akan langsung diterima oleh member melalui sistem. Dapat dilihat pada Tabel 3.

Tabel 3 Icon Member

\begin{tabular}{|c|c|c|c|}
\hline No & Level & Icon & Point \\
\hline 1 & Beginner & & $\begin{array}{c}0- \\
1000\end{array}$ \\
\hline 2 & Elementary & & $\begin{array}{c}1001- \\
2500\end{array}$ \\
\hline 3 & Intermediate & & $\begin{array}{c}2501- \\
4500\end{array}$ \\
\hline 4 & Advanced & & $>4500$ \\
\hline
\end{tabular}

h. Promosi merupakan tata cara mendapatkan point tambahan untuk member Hanaka
Concept Store tanpa harus membeli produk Hanaka Concept Store. Member akan membantu mempublikasikan tentang produk Hanaka Concept Store. Bukti berupa screenshot foto publikasi akan diupload oleh member melalui halaman promosi. Lalu admin akan mengkonfirmasi hasil foto publikasi member tersebut, dan member tersebut akan mendapatkan point tambahan dari hasil publikasi ini. Selanjutnya member dapat melihat leaderboard untuk mengetahui hasil pencapaian point dari seluruh member Hanaka Concept Store.

i. Leaderboard akan menampilkan point member, level member, icon member. Pada leaderboard juga terdapat event dan quest yang berfungsi untuk memberi beberapa pengetahuan tentang tata cara mendapatkan point tambahan untuk member. Proses pemberian hadiah berdasarkan jumlah point yang diperoleh oleh member. Proses ini dilakukan oleh pihak Hanaka Concept Store tiap-tiap periode. Periode ini bisa selama tiga bulan, enam bulan, bahkan bisa hanya selama satu bulan, Leaderboard akan direset dan dikurangi setelah pemberian hadiah dilakukan. Pengujian Halaman Antar Muka Android dapat kita lihar pada Tabel 4.

Tabel 4 Pengujian Halaman Antar Muka Android

\begin{tabular}{|c|c|c|c|}
\hline \multicolumn{2}{|c|}{ Bagian Uji } & \multicolumn{2}{|l|}{ Halaman Member } \\
\hline No & Item Uji & $\begin{array}{l}\text { Output Yang Di } \\
\text { Harapkan }\end{array}$ & Action \\
\hline 1 & $\begin{array}{l}\text { Halaman } \\
\text { Beranda }\end{array}$ & $\begin{array}{l}\text { Menampilkan } \\
\text { halaman utama } \\
\text { yang berisi Produk } \\
\text { Hanaka Concept } \\
\text { Store }\end{array}$ & $\begin{array}{l}\text { Klik menu } \\
\text { beranda }\end{array}$ \\
\hline 2 & $\begin{array}{l}\text { Halaman } \\
\text { Login }\end{array}$ & $\begin{array}{l}\text { Menampilkan dan } \\
\text { memproses } \\
\text { member }\end{array}$ & $\begin{array}{l}\text { Klik Menu } \\
\text { Login/Registr } \\
\text { asi }\end{array}$ \\
\hline 3 & $\begin{array}{l}\text { Halaman } \\
\text { Registrasi }\end{array}$ & $\begin{array}{l}\text { Menampilkan } \\
\text { halaman registrasi } \\
\text { member dan } \\
\text { memprosesnya }\end{array}$ & $\begin{array}{l}\text { Klik Menu } \\
\text { Login/Registr } \\
\text { asi }\end{array}$ \\
\hline 4 & $\begin{array}{l}\text { Halaman } \\
\text { Events }\end{array}$ & $\begin{array}{l}\text { Menampilkan } \\
\text { Halaman Events }\end{array}$ & $\begin{array}{l}\text { Klik Menu } \\
\text { Events }\end{array}$ \\
\hline 5 & $\begin{array}{l}\text { Halaman } \\
\text { Leader } \\
\text { Board }\end{array}$ & $\begin{array}{l}\text { Menampilkan } \\
\text { Halaman Leader } \\
\text { Board yang } \\
\text { menampilkan point, } \\
\text { level, badges dan } \\
\text { halaman quest }\end{array}$ & $\begin{array}{l}\text { Klik Menu } \\
\text { Leader } \\
\text { Board, Klik } \\
\text { Menu Quest } \\
\text { pada } \\
\text { halaman } \\
\text { Leaderboard }\end{array}$ \\
\hline 6 & $\begin{array}{l}\text { Halaman } \\
\text { About }\end{array}$ & $\begin{array}{l}\text { Menampilkan } \\
\text { Halaman About }\end{array}$ & $\begin{array}{l}\text { Klik Menu } \\
\text { About }\end{array}$ \\
\hline 7 & $\begin{array}{l}\text { Halaman My } \\
\text { Profile }\end{array}$ & $\begin{array}{lr}\text { Menampilkan dan } \\
\text { Mengupdate Data } \\
\text { Profile member }\end{array}$ & $\begin{array}{l}\text { Klik Menu } \\
\text { Update Data }\end{array}$ \\
\hline 8 & $\begin{array}{l}\text { Halaman } \\
\text { Daftar }\end{array}$ & $\begin{array}{l}\text { Menampilkan } \\
\text { halaman alamat, }\end{array}$ & $\begin{array}{l}\text { Klik Tambah } \\
\text { alamat, }\end{array}$ \\
\hline
\end{tabular}




\begin{tabular}{|c|l|l|l|}
\hline & Alamat & $\begin{array}{l}\text { menambahkan } \\
\text { serta mengupdate } \\
\text { alamat member }\end{array}$ & $\begin{array}{l}\text { simpan dan } \\
\text { Update } \\
\text { alamat }\end{array}$ \\
\hline 9 & $\begin{array}{l}\text { Halaman } \\
\text { Keranjang } \\
\text { Belanja }\end{array}$ & $\begin{array}{l}\text { Menampilkan dian } \\
\text { Produk yang dibeli } \\
\text { oleh member }\end{array}$ & $\begin{array}{l}\text { Klik } \\
\text { Checkout, } \\
\text { pilih alamat } \\
\text { lalu klu } \\
\text { selesai } \\
\text { belanja }\end{array}$ \\
\hline 10 & $\begin{array}{l}\text { Halaman } \\
\text { Histori } \\
\text { Pemesanan }\end{array}$ & $\begin{array}{l}\text { Menampilkan Histori } \\
\text { dan } \\
\text { Pemesanan Detail }\end{array}$ & $\begin{array}{l}\text { Klik Menu } \\
\text { Histori } \\
\text { Pemesanan }\end{array}$ \\
\hline 11 & $\begin{array}{l}\text { Halaman } \\
\text { Histori } \\
\text { Pembayaran }\end{array}$ & $\begin{array}{l}\text { Menampilkan Detail } \\
\text { Pembayaran dan } \\
\text { Konfirmasi } \\
\text { Pembayaran }\end{array}$ & $\begin{array}{l}\text { Klik Menu } \\
\text { Histori } \\
\text { Pembayaran } \\
\text { Temban Klik }\end{array}$ \\
& & $\begin{array}{l}\text { Tambah } \\
\text { Untuk } \\
\text { melakukan } \\
\text { Konfirmasi } \\
\text { Pembayaran }\end{array}$ \\
\hline 12 & $\begin{array}{l}\text { Halaman } \\
\text { Promosi }\end{array}$ & $\begin{array}{l}\text { Menampilkan } \\
\text { Halaman promosi } \\
\text { dan upload promosi }\end{array}$ & $\begin{array}{l}\text { Klik Menu } \\
\text { Promosi, } \\
\text { Upload data }\end{array}$ \\
\hline 13 & Halaman \\
Log Out & $\begin{array}{l}\text { Keluar dari status } \\
\text { login sistem }\end{array}$ & Klik Log Out \\
\hline
\end{tabular}

Pengujian Halaman Antar Muka Android dapat kita lihar pada Tabel 5.

Tabel 5 Pengujian Halaman Admin

\begin{tabular}{|c|c|c|c|}
\hline \multicolumn{2}{|c|}{ Bagian Uji } & \multicolumn{2}{|l|}{ Halaman Admin } \\
\hline $\begin{array}{l}\mathbf{N} \\
\mathbf{O}\end{array}$ & Item Uji & $\begin{array}{l}\text { Output Yang Di } \\
\text { Harapkan }\end{array}$ & Action \\
\hline 1 & $\begin{array}{l}\text { Halaman } \\
\text { Login } \\
\text { Admin }\end{array}$ & $\begin{array}{lr}\text { Menampilkan } & \text { dan } \\
\text { memproses } & \text { login } \\
\text { admin } & \end{array}$ & $\begin{array}{l}\text { Klik menu } \\
\text { Log In }\end{array}$ \\
\hline 2 & $\begin{array}{l}\text { Halaman } \\
\text { Home } \\
\text { Admin }\end{array}$ & $\begin{array}{l}\text { Menampilkan } \\
\text { halaman utama } \\
\text { admin }\end{array}$ & $\begin{array}{l}\text { Klik Menu } \\
\text { Administrator }\end{array}$ \\
\hline 3 & $\begin{array}{l}\text { Halaman } \\
\text { Kategori }\end{array}$ & $\begin{array}{l}\text { Menampilkan } \\
\text { Halaman Kategori }\end{array}$ & $\begin{array}{l}\text { Klik menu } \\
\text { Kategori }\end{array}$ \\
\hline 4 & $\begin{array}{l}\text { Halaman } \\
\text { Produk }\end{array}$ & $\begin{array}{l}\text { Menampilkan } \\
\text { Halaman Produk }\end{array}$ & $\begin{array}{l}\text { Klik Menu } \\
\text { Produk }\end{array}$ \\
\hline 5 & $\begin{array}{l}\text { Halaman } \\
\text { Home } \\
\text { Slider }\end{array}$ & $\begin{array}{l}\text { Menampilkan } \\
\text { Halaman Home } \\
\text { Slider }\end{array}$ & $\begin{array}{l}\text { Klik Menu } \\
\text { Home Slider }\end{array}$ \\
\hline 6 & $\begin{array}{l}\text { Halaman } \\
\text { User }\end{array}$ & $\begin{array}{ll}\text { Menampilkan } & \text { Data } \\
\text { User } & \text { Yang } \\
\text { menggunakan } & \\
\text { Halaman Admin }\end{array}$ & $\begin{array}{ll}\text { Klik } & \text { Menu } \\
\text { User } & \end{array}$ \\
\hline 7 & $\begin{array}{l}\text { Halaman } \\
\text { Kota }\end{array}$ & $\begin{array}{l}\text { Menampilkan } \\
\text { Master Data Kota }\end{array}$ & $\begin{array}{ll}\text { Klik } & \text { Menu } \\
\text { kota } & \end{array}$ \\
\hline 8 & $\begin{array}{l}\text { Halaman } \\
\text { Bank }\end{array}$ & $\begin{array}{l}\text { Menampilakan } \\
\text { Master Data Bank }\end{array}$ & $\begin{array}{ll}\text { Klik } & \text { Menu } \\
\text { Bank } & \\
\end{array}$ \\
\hline 9 & $\begin{array}{l}\text { Halaman } \\
\text { Rekening }\end{array}$ & $\begin{array}{l}\text { Menampilkan } \\
\text { Master Dat } \\
\text { Rekening }\end{array}$ & $\begin{array}{l}\text { Klik Menu } \\
\text { Rekening }\end{array}$ \\
\hline 10 & $\begin{array}{l}\text { Halaman } \\
\text { Member }\end{array}$ & $\begin{array}{l}\text { Menampilkan } \\
\text { Seluruh } \\
\text { Member }\end{array}$ & $\begin{array}{l}\text { Klik Menu } \\
\text { Member }\end{array}$ \\
\hline 11 & $\begin{array}{l}\text { Halaman } \\
\text { Events }\end{array}$ & $\begin{array}{l}\text { Menampilkan } \\
\text { Halaman Event, } \\
\text { Menambah, } \\
\text { Mengedit, dan } \\
\text { Menghapus Data } \\
\text { Events }\end{array}$ & $\begin{array}{l}\text { Klik Menu } \\
\text { Events, } \\
\text { tambah, edit, } \\
\text { hapus data }\end{array}$ \\
\hline 12 & Halaman & Menampilkan & Menu \\
\hline
\end{tabular}

\begin{tabular}{|c|c|c|c|}
\hline & Quest & $\begin{array}{lr}\text { Halaman } & \text { Quest, } \\
\text { Menambah, } \\
\text { Mengedit, dan } \\
\text { Menghapus } \\
\text { Quest }\end{array}$ & $\begin{array}{l}\text { Quest } \\
\text { tambah, edit, } \\
\text { hapus data }\end{array}$ \\
\hline 11 & $\begin{array}{l}\text { Halaman } \\
\text { Leaderboar } \\
\text { d }\end{array}$ & $\begin{array}{lr}\text { Menampilkan } & \text { Point } \\
\text { Dari } & \text { Seluruh } \\
\text { Member } & \text { dan } \\
\text { memungkinkan } \\
\text { admin } & \text { untuk } \\
\text { mereset } & \text { point } \\
\text { tersebut } & \end{array}$ & $\begin{array}{l}\text { Klik Menu } \\
\text { Leaderboard, } \\
\text { reset point }\end{array}$ \\
\hline 12 & $\begin{array}{l}\text { Halaman } \\
\text { List } \\
\text { Penjualan }\end{array}$ & $\begin{array}{l}\text { Menampilkan Data } \\
\text { Detil Penjualan }\end{array}$ & $\begin{array}{l}\text { Klik menu } \\
\text { Penjualan }\end{array}$ \\
\hline 13 & $\begin{array}{l}\text { Halaman } \\
\text { List } \\
\text { Pembayara } \\
n\end{array}$ & $\begin{array}{l}\text { Menampilkan Data } \\
\text { Detil Pembayaran }\end{array}$ & $\begin{array}{l}\text { Klik Menu } \\
\text { Pembayaran }\end{array}$ \\
\hline 14 & $\begin{array}{l}\text { Halaman } \\
\text { Lap.Penjual } \\
\text { an }\end{array}$ & 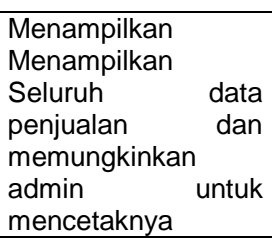 & $\begin{array}{l}\text { Klik } \quad \text { Menu } \\
\text { Lap.Penjuala } \\
\text { n, } \quad \text { cetak } \\
\text { laporan }\end{array}$ \\
\hline 15 & $\begin{array}{l}\text { Halaman } \\
\text { Lap.pemba } \\
\text { yaran }\end{array}$ & $\begin{array}{ll}\text { Menampilkan } & \\
\text { Seluruh } & \text { data } \\
\text { penjualan dan } \\
\text { memungkinkan } \\
\text { admin } \\
\text { mencetaknya }\end{array}$ & $\begin{array}{l}\text { Klik } \\
\text { Lap.Pembay } \\
\text { aran, cetak } \\
\text { laporan }\end{array}$ \\
\hline 16 & $\begin{array}{l}\text { Halaman } \\
\text { Promosi }\end{array}$ & $\begin{array}{lr}\text { Menampilkan data } \\
\text { promosi yang } \\
\text { dilakukan member }\end{array}$ & $\begin{array}{l}\text { Klik Menu } \\
\text { Promosi }\end{array}$ \\
\hline 16 & $\begin{array}{l}\text { Halaman } \\
\text { Log Out }\end{array}$ & $\begin{array}{ll}\text { Keluar dari status } \\
\text { login sistem }\end{array}$ & $\begin{array}{l}\text { Klik Menu } \\
\text { Log Out }\end{array}$ \\
\hline
\end{tabular}

\subsection{Usability Testing}

Usability testing merupakan kegiatan yang dilakukan secara interatif untuk mendapatkan respon yang komprehensif dari pengguna aplikasi. Teknik ini dapat digunakan dengan cara menentukan user, melakukan pemilihan fungsi, membuat tugas usability testing, menentukan waktu usability testing, melaksanakan usability testing, melakukan analisa data dengan cara merekam atau mencatat hasil dari usability testing, melakukan pengukuran usability dengan menggunakan kuisioner, dan terakhir melakukan analisis untuk rekomendasi perbaikan sistem ke depannya.

\subsection{Tanggapan Pelanggan}

Berikut ini akan disampaikan tabel mengenai total skor tanggapan tamu secara keseluruhan terhadap masing-masing dimensi pelayanan dapat dilihat pada Tabel 6 .

Tabel 6 Rekapitulasi Penilaian Pelanggan Terhadap Gamification Hanaka 


\begin{tabular}{|c|c|c|c|}
\hline No & Deskripsi & $\begin{array}{l}\text { Rata- } \\
\text { rata }\end{array}$ & Keterangan \\
\hline 1 & $\begin{array}{l}\text { Point Pada } \\
\text { Gamification } \\
\text { Hanaka }\end{array}$ & 4,6 & Sangat Setuju \\
\hline 2 & $\begin{array}{l}\text { Sistem Point Untuk } \\
\text { Member Hanaka }\end{array}$ & 4,55 & Sangat Setuju \\
\hline 3 & $\begin{array}{l}\text { Menjadi Leader } \\
\text { (pemimpin) dalam } \\
\text { Leaderboard } \\
\text { Hanaka }\end{array}$ & 4,1 & Setuju \\
\hline 4 & $\begin{array}{l}\text { Quest dan Event } \\
\text { pada Gamification } \\
\text { Hanaka }\end{array}$ & 4,45 & Sangat Setuju \\
\hline 5 & $\begin{array}{l}\text { Menyelesaikan } \\
\text { Quest dan Event } \\
\text { pada gamification } \\
\text { Hanaka }\end{array}$ & 4,4 & Sangat Setuju \\
\hline 6 & $\begin{array}{l}\text { Sistem promosi } \\
\text { pada gamification } \\
\text { Hanaka untuk } \\
\text { mendapatkan point } \\
\text { tambahan }\end{array}$ & 4,45 & Sangat Setuju \\
\hline 7 & $\begin{array}{l}\text { Icon dan Level } \\
\text { pada leaderboard } \\
\text { menarik }\end{array}$ & 4,35 & Sangat Setuju \\
\hline & Rata-rata & 4,41 & Sangat Setuju \\
\hline
\end{tabular}

Sumber: Tabulasi hasil kuisioner tahun 2017 (Data diolah)

Dari Tabel 6 diatas dapat dilihat total skor dari tanggapan pelanggan terhadap sistem gamification pada Hanaka Concept Store 4,41. Berdasarkan total skor tersebut maka, tanggapan-tanggapan pelanggan terhadap sistem gamification pada Hanaka Concept Store dapat dikategorikan sangat setuju dengan adanya sistem gamification tersebut karena berada di interval 4.21 - 5.00. Tabulasi hasil kuisioner Gamification pada Hanaka Concept Store bisa kita lihat pada lampiran.

\section{SIMPULAN}

Berdasarkan hasil pengujian aplikasi dan pembahasan sebelumnya maka diperoleh beberapa simpulan sebagai berikut:

1. Konsep gamification pada hanaka concept store telah dibangun dan mampu diterapkan dalam pembuatan sistem penjualan online.

2. Sistem ini mempermudah dalam hal proses manajemen data barang dan data penjualan, serta pengolahan data yang cepat dan terkomputerisasi serta mempermudah costumer yang memiliki kendala waktu dan jarak dengan adanya fasilitas penjualan online.

3. Sistem ini terdapat fitur gamification yang dapat membuat menarik customer untuk melakukan aktifitas pada sistem baik itu melakukan transaksi maupun tugas-tugas yang menghasilkan banyak point, dimana point-point yang terkumpul dapat ditukarkan hadiah.

\section{Daftar Pustaka}

[1] R. Hendariningrum, "Fashion Dan Gaya Hidup : Identitas Dan Komunikasi," J. IImu Komun., no. Vol 6, No 1 (2008), 2008.

[2] L. A. B. Silvatika Gregorius Satia; Gunawan, Ibnu, "Perancangan Dan Pembuatan Aplikasi Ecommerce Pada Toko Agung Jaya," J. Infra, no. Vol 1, No 2 (2013), p. pp.72-p.75, 2013.

[3] Bunchball Inc., Gamification 101: An Introduction to the Use of Game Dynamics to Influence Behavior. Redwood City: Bunchball Inc, 2010.

[4] S. S. Ambar Pratiwi I.Made; Adi Purnawan, I.Ketut, "Rancang Bangun Aplikasi Sistem Pemesanan Bunga Berbasis Android," Merpati, no. Vol. 2, No. 2, Agustus 2014, 2014.

[5] R. P. W. Hastanti Indah Ully, "Analisis Dan Perancangan Sistem Penjualan Berbasis Web (E-Commerce) Pada Tata Distro Kabupaten Pacitan," IJNS - Indones. J. Netw. Secur., no. IJNS-Accepted Paper, 2013.

[6] Radityo Prasetianto Wibowo; Fachri Hilmi Romdhoni, "Purwarupa Aplikasi Pembelajaran SQL Interaktif Berbasis Web Dengan Penerapan Gamification," J. SISFO Inspirasi Prof. Sist. Inf., no. Volume 5, Number 3, 2015, pp. 390-397, 2015.

[7] G. Zichermann and C. Cunningham, Gamification by Design: Implementing Game Mechanics in Web and Mobile Apps. Canada: O'Reilly Media, 2011. 